\title{
Using segmentation to support the learning from animated soccer scenes: An effect of prior knowledge
}

Citation for published version (APA):

Khacharem, A., Spanjers, I. A. E., Zoudji, B., Kalyuga, S., \& Ripoll, H. (2013). Using segmentation to support the learning from animated soccer scenes: An effect of prior knowledge. Psychology of Sport and Exercise, 14(2), 154-160. https://doi.org/10.1016/j.psychsport.2012.10.006

Document status and date:

Published: 01/03/2013

DOI:

10.1016/j.psychsport.2012.10.006

Document Version:

Publisher's PDF, also known as Version of record

Document license:

Taverne

Please check the document version of this publication:

- A submitted manuscript is the version of the article upon submission and before peer-review. There can be important differences between the submitted version and the official published version of record.

People interested in the research are advised to contact the author for the final version of the publication, or visit the DOI to the publisher's website.

- The final author version and the galley proof are versions of the publication after peer review.

- The final published version features the final layout of the paper including the volume, issue and page numbers.

Link to publication

\footnotetext{
General rights rights.

- You may freely distribute the URL identifying the publication in the public portal. please follow below link for the End User Agreement:

www.umlib.nl/taverne-license

Take down policy

If you believe that this document breaches copyright please contact us at:

repository@maastrichtuniversity.nl

providing details and we will investigate your claim.
}

Copyright and moral rights for the publications made accessible in the public portal are retained by the authors and/or other copyright owners and it is a condition of accessing publications that users recognise and abide by the legal requirements associated with these

- Users may download and print one copy of any publication from the public portal for the purpose of private study or research.

- You may not further distribute the material or use it for any profit-making activity or commercial gain

If the publication is distributed under the terms of Article $25 \mathrm{fa}$ of the Dutch Copyright Act, indicated by the "Taverne" license above, 


\title{
Using segmentation to support the learning from animated soccer scenes: An effect of prior knowledge
}

\author{
Aïmen Khacharem ${ }^{\text {a,b,*}}{ }^{\text {, Ingrid A.E. Spanjers }}{ }^{c}$, Bachir Zoudji ${ }^{\text {b,d }}$, Slava Kalyuga ${ }^{e}$, Hubert Ripoll ${ }^{\text {a,b }}$ \\ ${ }^{a}$ Faculty of Sport Sciences, Aix-Marseille University, France \\ ${ }^{\mathrm{b}}$ Information and System Sciences Laboratory, UMR-CNRS 6168, France \\ ${ }^{\mathrm{c}}$ Department of Educational Development and Research $\mathcal{E}$ School of Health Professions Education, Maastricht University, The Netherlands \\ ${ }^{\mathrm{d}}$ Faculty of Sport Sciences and Management, University of Valenciennes and Hainaut Cambrésis, France \\ e School of Education, University of New South Wales, Sydney, NSW 2052, Australia
}

\section{A R T I C L E I N F O}

\section{Article history:}

Received 25 March 2012

Received in revised form

5 October 2012

Accepted 10 October 2012

Available online 26 October 2012

\section{Keywords:}

Animations

Learning

Segmentation

Expertise

Soccer

Cognitive load theory

\begin{abstract}
A B S T R A C T
Objectives: We used a cognitive load perspective to investigate the effects of levels of learner expertise and different forms of segmentation in learning from animated soccer scenes.

Method: Expert and novice players $(N=48)$ completed a recall reconstruction-test and rated their invested mental effort after studying a continuous animation, a macro-step and a micro-step segmented animation.

Results: Findings demonstrated an expertise reversal effect for segmentation. It positively affected learning outcomes of novices but not experts (even though they still invested less mental effort and repeated the animation less often in the two segmented conditions). Additionally, novices benefited more from micro-step segmentation than from macro-step segmentation, while experts performed at the same level with both forms of segmentation.

Conclusions: Study results suggested that adapting instructional animation formats to players with different levels of expertise should be a crucial part of successful training.
\end{abstract}

(c) 2012 Elsevier Ltd. All rights reserved.
The key feature of team sports, such as soccer, is that they are dynamic, meaning that situations of play change continuously over time, and information available at one moment is not available in the next moment. Animations are considered to be the most convenient instructional media for demonstrating explicitly these situations (Tversky, Morrison, \& Betrancourt, 2002). Both coaches and educators assume that animations are more effective than static pictures because an observer can directly perceive players' movement in the field (e.g., motion, acceleration, trajectory) rather than having to mentally infer them (e.g., using mental animation, Hegarty, 1992). Furthermore, since animations are usually very appealing and attractive, they can also increase learners' motivation (Barak, Ashkar, \& Doro, 2011; Chandler, 2009).

However, despite these assumptions, many studies have concluded that animations are at best no more effective, and sometimes even less effective for learning than static pictures (e.g.,

\footnotetext{
* Corresponding author. Faculté des Sciences du Sport, Case Postale 910, 163 Avenue de Luminy 13288 - Marseille, France. Tel.: +33642103201.

E-mail address: aimen.khacharem@gmail.com (A. Khacharem).
}

Boucheix \& Schneider, 2009; Hegarty, Kriz, \& Cate, 2003; Mayer, Hegarty, Mayer, \& Campbell, 2005; Tversky et al., 2002). It has also been demonstrated that some types of animations that are representative (i.e., the content to be learned is explicitly depicted in the animation vs. animations serving purely decorative roles), realistic, and involve procedural-motor knowledge may be more effective for learning than static visualizations (Höffler \& Leutner, 2007; Van Gog, Paas, Marcus, Ayres, \& Sweller, 2009).

In order to improve learning from the animations, a number of design guidelines have been proposed (for reviews, see Mayer \& Moreno, 2003; Wouters, Paas, \& Van Merriënboer, 2008). One of these design guidelines is segmentation which recommends showing animations in pieces rather than a continuous flow of information (Mayer \& Moreno, 2003; Moreno \& Mayer, 2007; Spanjers, Van Gog, \& Van Merriënboer, 2010). However, research within a cognitive load framework has demonstrated that design guidelines which are effective for novices may have no effect, or even a negative effect, for more advanced learners. This phenomenon is called the expertise reversal effect (for reviews, see Kalyuga, 2007; Kalyuga, Ayres, Chandler, \& Sweller, 2003; Kalyuga, Rikers, \& Paas, 2012). Accordingly, a number of studies have indicated the 
occurrence of an expertise reversal effect with regard to segmentation of dynamic visualizations (Schnotz, 2002; Spanjers, Wouters, Van Gog, \& Van Merriënboer, 2011).

The aim of the present study is to investigate the effectiveness of different forms of segmented animations in learning a sequence of play in soccer. An important part of this aim is to establish whether the effectiveness of segmentation is influenced by levels of learner prior knowledge (levels of expertise).

\section{Cognitive demands of learning from animations}

Learning from a complex external display such as an animation involves the construction of an internal mental model that accurately represents the referents of the external display (Kriz \& Hegarty, 2007). Animations are often not easy to understand because they impose high cognitive demands that exceed the learners' limited working memory (WM) capacity, resulting in a cognitive overload (overwhelming, Lowe, 1999; 2004). Inversely, animation may decrease learners' cognitive engagement (underwhelming, Lowe, 2004) and lead to an illusion of understanding (Bétrancourt, 2005).

Cognitive load theory (Sweller, 2005; Sweller, Ayres, \& Kalyuga, 2011; Sweller, van Merriënboer, \& Paas, 1998; Van Merriënboer \& Sweller, 2005) suggests that learning from animations often fails because they are not designed in alignment with human cognitive architecture. This architecture includes WM with limited duration and capacity (Baddeley, 2003) when dealing with unfamiliar information, and long-term memory (LTM) with an unlimited capacity. There are different categories of cognitive load experienced by learners. Intrinsic cognitive load is inherent to the learning material. It depends on the number of information elements and their interactions that must be processed simultaneously. Intrinsic load is always influenced by levels of learner expertise. Domain-specific knowledge structures stored in longterm memory allow experts to encapsulate large amounts of information in larger chunks that are processed as single items, thus reducing intrinsic cognitive load. Extraneous cognitive load, in contrast, is not inherent to the learning material but depends on the design of material, and it is imposed by presented information and required activities that impede the learning process. This load causes learners to unproductively waste their limited working memory resources on tasks and activities that are not directly related to learning. Working memory resources that are devoted to dealing with productive, intrinsic cognitive load are referred to as germane cognitive resources (Sweller et al., 2011). In instruction, it is important to increase germane resources and decrease unproductive waste of working memory resources (e.g., Sweller et al., 1998; Van Merriënboer \& Sweller, 2005).

According to cognitive load theory, animations often generate high extraneous cognitive load because the presented information is transient, meaning that information presented at one moment makes place in WM for new information presented at the next moment (e.g., Ainsworth \& Van Labeke, 2004; Ayres \& Paas, 2007; Mayer \& Moreno, 2003; Moreno \& Mayer, 2007; transient information effect in Sweller et al., 2011). When viewing transient animations, learners are required to process current information while simultaneously trying to maintain previous information and integrate it with new information and knowledge in LTM. If current and previous information have to be considered simultaneously, comprehension may be problematic because of the temporal limitations of WM (Ayres \& Paas, 2007; Hasler, Kersten, \& Sweller, 2007).

Animations consist of series of successive frames or pictures. If picture $A$ is learned first and followed by picture $B$, learning of picture $B$ may interfere with and impede the recall of $A$. This phenomenon is called interference or retroactive inhibition (Mayer, DeLeeuw, \& Ayres, 2007). Furthermore, animations portraying the functioning of dynamical systems (e.g., tactical systems of play) often show several elements that change simultaneously with respect to their position and orientation (De Koning, Tabbers, Rikers, \& Paas, 2007, 2010). Consequently, learners have to spatially and temporally split their visual attention over the visual display and continuously decide "what to look, when to look and where to look" (Lowe, 2003; 2004; Schnotz \& Lowe, 2008). These cognitive processes may also overwhelm learner cognitive system.

\section{Segmentation effect and levels of learner expertise}

A possible way to reduce extraneous cognitive load imposed by an animation is to use the segmentation technique by dividing the animation into a set of meaningful sequential units/pieces (e.g., Schnotz \& Lowe, 2008; Spanjers et al., 2010). By inserting pauses or time breaks between the segments, learners are provided with additional time to process and integrate information received in the previous segments without the need to simultaneously attend to newly incoming information (Mayer \& Chandler, 2001; Mayer \& Moreno, 2003; Spanjers et al., 2010). This technique may alleviate the high extraneous cognitive load imposed by the animation's transience. Furthermore, segmentation may be seen as a form of temporal cueing (Spanjers et al., 2010), because it allows highlighting micro- and/or macro-events in an animation (Meyer, Rasch, \& Schnotz, 2010; Zacks \& Tversky, 2001) thus facilitating the construction of well-structured and organized knowledge in LTM.

Several studies have found beneficial effects of segmentation for novice learners, particularly in enhancing performance (Boucheix \& Schneider, 2009; Hasler et al., 2007; Mayer \& Chandler, 2001; Mohamad Ali, 2010; Moreno, 2007; Spanjers, Van Gog, Wouters, \& Van Merriënboer, 2012) and in reducing invested mental effort (Moreno, 2007; Spanjers et al., 2012, 2011). However, the recent study by Spanjers et al. (2011) has demonstrated that the effect of segmentation is influenced by levels of learner expertise. Learners with different levels of prior knowledge were presented with either non-segmented animations (N-SA) on probability calculation or animations that were segmented through 2-s pauses (SA) after which the animations continued automatically. The results indicated a significant interaction between levels of learner expertise and instructional conditions on mental effort invested in studying the animations and learning efficiency (i.e., an expertise reversal effect for segmentation; Kalyuga, 2007; Kalyuga et al., 2003). Learners with lower levels of prior knowledge required less mental effort to achieve a similar level of performance from SA than from $\mathrm{N}-\mathrm{SA}$, while more knowledgeable learners who had presumably already acquired a sufficient knowledge base for dealing with the transitivity of the animations, invested the same amount of mental effort in N-SA and SA to achieve a similar level of performance.

\section{The rationale of the study}

According to the studies mentioned above, the effectiveness of the learning process is dependent not only on the presentation form of the animation, but also on the learners' level of expertise in the field. To investigate the potential interaction between these two factors, we used soccer game activity, and particularly a counterattack scene. This type of soccer attack involves a restricted number of players (approximately 6 players i.e., the midfielders and attackers) who should carry out a rapid tactical combination of play composed of a limited number of forward passes (approximately 5 passes) toward the opposition goal. During each pass, each player 
should move in relation to the ball and the teammates' positions in order to offer an appropriate solution to the ball carrier.

In this study, we used a recall reconstruction-test (Chase \& Simon, 1973) and a mental effort rating scale (Paas, 1992) to determine whether segmenting a complex animation of an offensive sequence of soccer would result in better learning outcomes, lower mental effort and lower numbers of required repetitions than presenting the same animation without segmentation. Two forms of segmentation were tested: micro-step segmentation and macro-step segmentation. While macro-step segmentation consists of inserting pauses after the movement of all team players during a phase of play, micro-step segmentation consists of inserting pauses after the movement of a specific group of players during a phase of play. It was hypothesized that expert soccer players who had already acquired domain-specific knowledge to deal with extraneous cognitive load induced by transient animation (Kalyuga, 2008; Spanjers et al., 2011), would perform at the same level, invest the same amount of mental effort and need the same number of repetitions regardless of the type of presentation. However, novice soccer players would benefit from the segmented animation by either achieving higher recall scores, investing less mental effort, requiring fewer repetitions during learning, or demonstrating a combination of these. We also predicted that micro-step segmentation would lead to more efficient learning (i.e., higher/equal learning outcomes would be achieved with equal/lower mental effort and equal/smaller number of repetitions) than macro-step segmentation for novices because more pauses would result in less information processed simultaneously in WM.

\section{Method}

\section{Participants}

A group of 24 novice male soccer players and a group of 24 expert male soccer players volunteered to participate in the experiment. The novice participants $\left(M_{\mathrm{age}}=26.22, S D=2.6\right)$ had never practiced team sports in a club and only participated in occasional soccer games in physical education classes or with friends. The experts $\left(M_{\mathrm{age}}=25.84, S D=3.2\right)$ were all professional soccer players who had been playing on a top-level team engaged in a national competition. They had been playing soccer for an average of 12.7 years $(S D=2.0)$ for an average of 45 match competitions $(S D=3.29)$ per year and trained or played for an average of $9.54 \mathrm{~h}(S D=1.58)$ per week.

\section{Apparatus and material}

The experiment was conducted using an HP Pavilion dv6 computer. The stimuli were presented on a $250 \mathrm{~cm} \times 200 \mathrm{~cm}$ screen from a video projection system (Sony VPL EX120 XGA) placed at a distance of $3 \mathrm{~m}$. The image on the screen was $200 \mathrm{~cm} \times 160 \mathrm{~cm}$, with a $45^{\circ}$ viewing angle.

Three different animated soccer offensive plays were designed in cooperation with three expert soccer coaches using SimulFoot 3D software. ${ }^{1}$ Each animation contained six offensive players and a goal keeper. The players performed a tactical combination of play composed of five passes before shooting on goal. During each pass (a game phase), many actions were made by players (e.g., motions, cross, overlaps). Each animation was captured as if it was recorded by a sideline camera (approximate distance $13 \mathrm{~m}$ ) in an elevated

\footnotetext{
1 SimulFoot was developed by researchers from the SimGraph team of the Information Science and Systems Laboratory (LSIS) at Aix-Marseille University.
}

position (approximate height $9 \mathrm{~m}$ ), with a $20^{\circ}$ viewing angle. This camera position enabled the entire field of play to be viewed.

Besides a non-segmented animation which was presented without interruptions (32 s of duration), we generated two different forms of segmented animations: macro-step and microstep segmentations. In the macro-step segmentation condition, the animation was divided into six segments with five pauses of $2 \mathrm{~s}$ between them. In this version, each of the five passes corresponded to one step that showed participants the movement of all players. The last segment was shooting on goal. The duration of this version was $42 \mathrm{~s}$. In the micro-step segmentation, the animation was divided into eleven segments with ten pauses of $2 \mathrm{~s}$ between them (one macro-step was made up of two micro-steps). In this version, each of the five passes corresponded to two different steps. Each step showed participants only the movement of a small group composed of two, three or four players. Each micro-step represents a chunk i.e., a meaningful grouping of players with a specific function as defined by the same coaches. The duration of this version was $52 \mathrm{~s}$.

\section{Procedure and task}

Participants took part in the experiment individually (45 min). Each participant was presented successively with the three forms of animations. The order of the three conditions was counterbalanced within-groups (all participants were exposed to all conditions). The procedure consisted of two phases: a study phase and a test phase.

Study Phase. The participants were instructed to study the sequence of play to be able to reconstruct it later as accurately as possible. First, a preparation message (Ready!) was displayed on the screen for $2 \mathrm{~s}$. As soon as the message disappeared, an animation of a sequence of play was projected. Once the sequence ended, the participant had the option of repeating the animation as many times as he wanted by clicking on the "Repeat" button. When the participant believed he understood the animation, he had to click on the "End" button. Animations were not accompanied by any verbal explanations (written and/or oral). This was done to avoid the potential influence of modality, redundancy or temporal continuity effects associated with the simultaneous use of visual and verbal information (Kalyuga, 2008).

Test Phase. After the study phase for each version of the animation, the participants were asked to perform two successive tasks. (i) Evaluate the mental effort invested in studying the animation on a 9-point subjective Likert rating scale, ranging from (1) very, very low mental effort to (9) very, very high mental effort (Paas, 1992; Paas, Tuovinen, Tabbers, \& Van Gerven, 2003). (ii) Reconstruct the situation of play by drawing it on a paper that contains an empty soccer field, with the same viewing angle as in the animations (see Fig. 1). The soccer field was divided into five parts. For each part, players were instructed to reconstruct as accurately as possible the position of the six players in relation to the ball already placed in the correct location. In each stage of play, they have to reproduce the position of the ball carrier, players located in front of the ball (at the left, the middle or the right), and players located behind the ball (at the left, the middle or the right). One point was awarded for each correct answer (correct placement of a player in the field); zero point was awarded for each wrong answer (incorrect placement of a player in the field). The scores could, therefore, range from 0 to 30 .

\section{Design}

The dependent variables were recall accuracy, number of repetitions, mental effort and learning efficiency. Instructional 


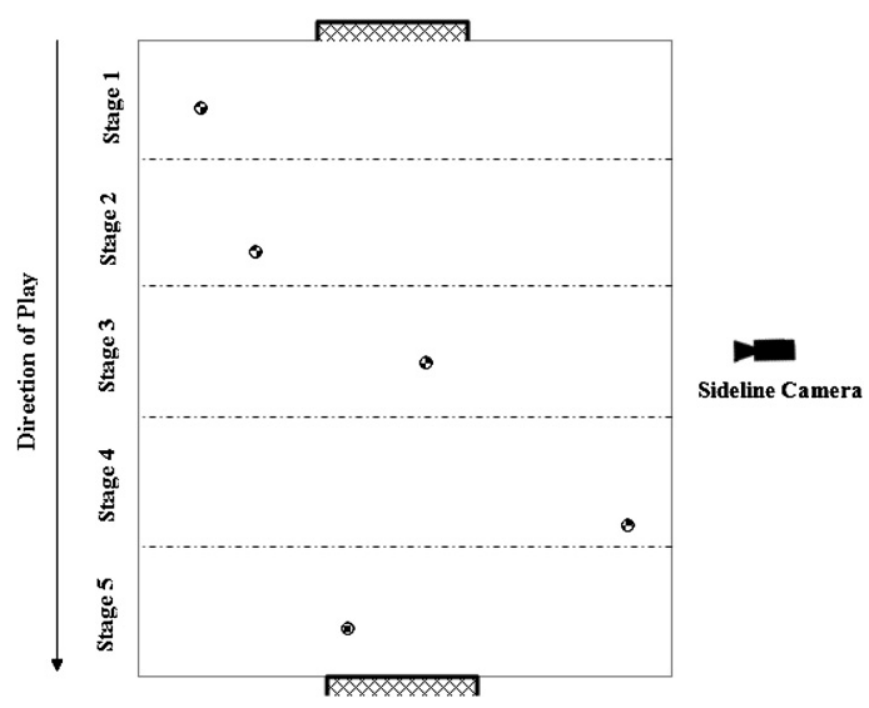

Fig. 1. Schematic presentation of the empty soccer play.

efficiency was calculated using Paas and Van Merriënboer's (1993) computational approach.

Efficiency $=\left({ }^{z}\right.$ recall $-{ }^{z}$ mental effort $) / \sqrt{2}$.

This measure combines standardized $z$-scores for the test performance scores with standardized $z$-scores for the ratings of mental effort associated with studying the materials. According to this definition of relative instructional efficiency, a lower rating of effort combined with higher performance scores would provide evidence of a more efficient learning condition. The denominator is used to make the graphical interpretation of the formula more straightforward by representing the mental effort and performance $z$-scores in a cross of axes. The relative efficiency at any point on the diagram can be measured as the distance from this point to the line of zero efficiency (recall $-{ }^{z}$ mental effort).

The data were analyzed using mixed design ANOVAs in which Condition (continuous, macro-step segmented, microstep segmented) was a within-subjects factor, and Expertise (expert vs. novice) was a between-subjects factor. GreenhouseGeisser adjusted results were used for the within-subjects factor and the interaction between the within-subjects factor and the between-subjects factor. The alpha level for significance was set at $p<.05$. To determine the source of any significant effects, for each dependent variable, three sets of further analyses with setwise Bonferroni-adjusted $p$-values were used. Effect sizes are reported as partial eta squared $\left(\eta_{p}^{2}\right)$ and Cohen's mean standardized differences (ES) for post-hoc comparisons.

\section{Results}

Descriptive statistics for recall accuracy, mental effort, number of repetitions and learning efficiency for novice and expert participants are presented in Table 1.

\section{Recall accuracy}

The analysis showed a significant effect of Expertise, $F$ $(1,46)=172.65, p<.001, \eta_{p}^{2}=79$, a significant effect of Condition, $F$ $(1.97,90.80)=14.44, p<.001, \eta_{p}^{2}=24$, and a significant interaction between these two factors, $F(1.97,90.80)=10.00, p<.001$, $\eta_{p}^{2}=18$. Post-hoc analyses for the expert group revealed no
Table 1

Means scores (Standard Deviations) concerning recall accuracy, mental effort, number of repetition, and learning efficiency for each experimental condition and level of expertise.

\begin{tabular}{lrrr}
\hline & Continuous & Macro-step & \multicolumn{1}{c}{ Micro-step } \\
\hline Expert & & & \\
Recall Accuracy & $25.83(1.79)$ & $26.63(1.44)$ & $26.17(1.09)$ \\
Mental Effort & $3.87(0.74)$ & $3.13(0.68)$ & $3.25(0.68)$ \\
Number of Repetitions & $4.17(0.70)$ & $2.96(0.69)$ & $3.13(0.74)$ \\
Learning Efficiency & $0.66(0.46)$ & $1.27(0.59)$ & $1.08(0.46)$ \\
Novice & & & \\
Recall Accuracy & $21.08(0.88)$ & $22.50(1.35)$ & $24.17(2.53)$ \\
Mental Effort & $6.17(1.13)$ & $5.25(0.90)$ & $4.58(0.58)$ \\
Number of Repetitions & $7.21(0.83)$ & $6.08(0.72)$ & $5.17(0.82)$ \\
Learning Efficiency & $-1.85(0.63)$ & $-0.98(0.70)$ & $-0.17(0.85)$ \\
\hline
\end{tabular}

significant differences between the three conditions: continuous/ macro-step segmented, $n s, E S=-0.49$; continuous/micro-step segmented, $n s, E S=-0.23$ and macro-step segmented $/$ micro-step segmented, $n s, E S=0.36$. The expert participants performed at the same level regardless of the condition in which they were. However, post-hoc analyses for the novice group showed significant differences between the three conditions: continuous/macrostep segmented, $p=.002$, ES $=-1.25$; continuous/micro-step segmented, $p<.001, E S=-1.63$; macro-step segmented $/$ microstep segmented $p=.018, E S=-0.82$. It was found that novice participants performed significantly better in the macro-step segmented condition and micro-step segmented condition than in the non-segmented condition. Furthermore, they performed significantly better in the micro-step segmented condition than in the macro-step segmented condition. Further analyses showed that the expert participants had significantly better recall scores than the novice participants in each of the conditions, continuous, $F(1,46)=136.61, p<.001, \eta_{p}^{2}=75$, macro-step segmented, $F(1,46)=104.80, p<.001, \eta_{p}^{2}=69$, micro-step segmented, $F(1,46)=12.64, p=.003, \eta_{p}^{2}=22$.

\section{Mental effort}

The analysis showed a significant effect of Expertise, $F$ $(1.46)=266.43, p<.001, \eta_{p}^{2}=85$, a significant effect of Condition, $F(1.77,81.57)=21.96, p<.001, \eta_{p}^{2}=32$, and a significant interaction between these two factors, $F(1.77,81.57)=4.35, p=.020$, $\eta_{p}^{2}=09$. Post-hoc analyses for expert participants revealed significant differences between conditions: continuous/macro-step segmented, $p=.002, E S=1.04$; continuous/micro-step segmented, $p=.024, E S=0.87$, but a non-significant difference between macrostep segmented/micro-step segmented, $n s, E S=-0.18$. The expert participants invested more mental effort in studying the continuous condition than in the two segmented conditions. Post-hoc analyses for the group of novices showed significant differences between the three conditions: continuous/macro-step segmented, $p=.039, E S=0.90$; continuous/micro-step segmented, $p<.001$, $E S=1.77$, and macro-step segmented/micro-step segmented, $p=.005, E S=0.89$. The novice participants invested more mental effort in studying the continuous animation than in studying the segmented animations. Additionally, they invested more mental effort in studying the macro-step segmented animation than in studying the micro-step segmented animation. Further analyses comparing mental effort invested by the expert and novice participants showed that in all conditions the novice participants had to invest significantly more mental effort than the expert participants, continuous, $F(1,46)=69.09, p<.001, \eta_{p}^{2}=60$, macrostep segmented, $F(1,46)=85.58, p<.001, \eta_{p}^{2}=65$, micro-step segmented, $F(1,46)=53.53, p<.001, \eta_{p}^{2}=54$. 


\section{Number of repetition}

The analysis showed a significant effect of Expertise, $F$ $(1.46)=430.17, p<.001, \eta_{p}^{2}=90$, a significant effect of Condition, $F$ $(1.95,89.86)=57.99, p<.001, \eta_{p}^{2}=56$, and a significant interaction between these two factors, $F(1.95,89.86)=8.15, p<.001, \eta_{p}^{2}=15$. Post-hoc analyses for the expert group showed significant differences between conditions: continuous/macro-step segmented, $p<.001, E S=1.74$; continuous/micro-step segmented, $p<.001$, $E S=1.44$, but a non-significant difference between macro-step segmented/micro-step segmented, ns; $E S=-0.24$. It was found that the expert group needed more repetitions in the continuous conditions than in the segmented conditions. Post-hoc analyses for the novice group showed significant differences between the three conditions: continuous/macro-step segmented, $p<.001, E S=1.45$, continuous/micro-step segmented, $p<.001, E S=2.47$, and macrostep segmented/micro-step segmented, $p<.001, E S=1.18$. It was found that the novice participants needed more repetitions in the continuous condition than in the two segmented conditions. Additionally, they needed more repetitions in the macro-step segmented condition than in the micro-step segmented condition. Further analyses comparing the number of repetition needed by the expert and novice participants showed that the novice participants repeated the animations more often than the experienced participants in each of the conditions, continuous, $F(1,46)=187.13$, $p<.001, \eta_{p}^{2}=80$, macro-step segmented, $F(1,46)=236.52$, $p<.001, \eta_{p}^{2}=84$, micro-step segmented, $F(1,46)=82.30, p<.001$, $\eta_{p}^{2}=64$.

\section{Learning efficiency}

The analysis showed a significant effect of Expertise, $F$ $(1.46)=413.14, p<.001, \eta_{p}^{2}=90$, a significant effect of Condition, $F$ $(1.93,88.81)=33.27, p<.001, \eta_{p}^{2}=42$, and a significant interaction between Expertise and Condition, $F(1.93,88.81)=12.63, p<.001$, $\eta_{p}^{2}=22$. The post-hoc analyses for the experts only showed significant differences between continuous/macro-step segmented conditions, $p=.002, E S=-1.16$, and continuous/micro-step segmented conditions, $p=.005, E S=-0.91$, but not between micro-step segmented/macro-step segmented conditions, $p=.81$, $E S=0.36$. Therefore, for the experts learning was more efficient in both segmented animations than in the continuous animation. The post-hoc analyses for the novices only showed significant differences between all three conditions: continuous/macro-step segmented, $p=.001, \quad E S=-1.31$, continuous/micro-step segmented, $p<.001, E S=-2.24$, and micro-step segmented/ macro-step segmented, $p<.001, E S=-1.04$. For the novices, the micro-step segmented condition was more efficient than the macro-step segmented condition which in turn, was more efficient than the continuous condition. Further analyses showed that in all conditions, learning was more efficient for the experts than for the novices: continuous, $F(1,46)=249.69, p<.001, \eta_{p}^{2}=84$, macrostep segmented, $F(1,46)=146.28, p<.001, \eta_{p}^{2}=76$, micro-step segmented $F(1,46)=40.09, p<.001, \eta_{p}^{2}=47$.

\section{Discussion}

This study investigated the effects of levels of learner expertise and different forms of segmentation in facilitating learning from animated soccer scenes. In general, the results demonstrate that, regardless of the format used to present the animated soccer scenes, the experts demonstrated higher efficiency than the novices, that is, they obtained better recall scores, invested less mental effort and needed less repetition. This is consistent with previous studies on expertise demonstrating the superiority of expert soccer players in memorization and/or decision-making tasks when they are tested with realistic, sport-specific tasks (e.g., Abernethy, Neal, \& Koning, 1994; Araújo, Travassos, \& Vilar, 2010; Pinder, Davids, Renshaw, \& Araújo, 2011).

In addition, the results show a positive effect of segmentation on the learning process of both novices and experts. Novices demonstrated better recall scores with reduced investment of mental effort and lower numbers of repetitions when they were presented with segmented animations than with continuous animations. As mentioned in the introduction, there are two possible reasons for the effectiveness of segmentation for novices. First, pauses interspersed between segments provide additional time to process information and thus reduce the probability of a cognitive overload. Second, segmentation divides animation into meaningful pieces of information which can help learners to distinguish the key stages in the situation of play (temporal cueing: Spanjers et al., 2010).

However, unlike our predictions and the results reported by Spanjers et al. (2011), expert soccer players benefited from the segmented animations as well. Despite performing at the same level on the recall test under the three conditions, they invested less mental effort and repeated the animation less often in the two segmented conditions. It is possible that the experimental materials used by Spanjers et al. (2011) were not sufficiently complex for more advanced learners who were able to cope with the constraints of the animations. Besides, since expert soccer players may develop dynamic perception of play situations due to extensive practice (Didierjean \& Marmèche, 2005), it is also conceivable that pauses prompted them to predict/anticipate (e.g., Carling, Reilly, \& Williams, 2008; Stratton, Reilly, Williams, \& Richardson, 2005) and/or to plan (Johnson \& Raab, 2003; Poplu, Baratgin, Mavromatis, \& Ripoll, 2003) future movements of players in the next segment. In this case, information presented in the next segment might provide explicit visual feedback to which these learners could compare their predictions or planning. Even though these activities might generate additional intrinsic cognitive load, this is a productive load that would increase germane resources thus facilitating learners' understanding of the sequence of play.

Finally, the results show significant interactions between levels of learner expertise and forms of presentation for recall scores, mental effort, and the number of repetitions. Expert soccer players obtained the same recall scores regardless of the condition in which they were, while novice soccer players achieved higher scores in the segmented conditions than in the non-segmented conditions and higher scores in the micro-step segmented condition than in the macro-step segmented condition. In regard to mental effort ratings and the number of repetitions, it was found that expert soccer players invested the same mental effort and needed the same number of repetition in the two segmented animations, while novice soccer players invested less mental effort and needed fewer repetitions in the micro-step segmented animation than in the macro-step segmented animation. Hence, evidence for the occurrence of an expertise reversal effect with segmentation method as well as with different forms of segmentation was found.

Micro-step segmented animations were found to support novice participants more than macro-step segmented animations. Microstep segmentations provided novices with more pauses and consequently, with less information to be processed in WM concurrently. By limiting the quantity of information presented and interactions between elements of information in each segment, less cognitive resources were required at each moment in time to construct a mental model of the soccer scene. Hence, the segmentation supports learners in coping with the transience of 
the animation. Besides, micro-step segmentation allows highlighting different meaningful pieces in each phase of play, which may help novice players to structure and organize information in LTM.

Although the cognitive load theory seems to be very influential in a variety of educational domains such as mathematics, science, accountancy and language (Sweller et al., 2011), there hardly have been any studies in the sport-related fields that have used it as a theoretical framework. Besides, participants in most of preceding studies were students ranging from primary school to university levels. The number of studies involving actual experts in corresponding domains is very restricted and definitely needs to be extended. This paper adds one more study to this number. Also, contrary to previous studies of segmentation (e.g., Boucheix \& Schneider, 2009; Hasler et al., 2007; Mayer \& Chandler, 2001; Mohamad Ali, 2010; Moreno, 2007; Spanjers et al., 2011, 2012), we used a within-subjects design with counterbalanced treatments rather than a between-subjects design. There are two explications for this choice. First, a within-subjects design with counterbalanced treatments may be more effective because it can control the amount of variability caused by individual differences. Second, considering the difficulty of obtaining professional soccer experts as participants, this design is more economical (requires fewer participants).

A limitation of this study was that the pauses inserted between segments led to a difference in study time between the three versions. The participants in the micro-step segmented version studied animations with a longer total duration than the participants in the other two versions, and the participants in the macrostep segmented version studied animations with a longer total duration than the learners in the continuous version. This does not imply, however, that this difference in learning time might have led to the differences in learning outcomes. Because the participants decided themselves whether and when to start the animations, they were given the possibility to take extra time after the complete animations. However, the statement that segmentation supports learning is more specific, as it predicts positive effects of giving learners extra time after each segment rather than after complete animations. Pauses after the complete animations may be ineffective, or less effective in reducing the cognitive load imposed on the participants than pauses after small pieces (segments). Additionally, pauses after the complete animation do not highlight the macro- and micro-events in the animations. Nevertheless, the effect of these differences in learning time should be taken into account in future studies.

Future studies should also uncover how and where soccer players with different levels of expertise distribute their gaze on the screen during the pauses in order to understand why the different forms of segmentation have different effects. This can be done using an eye-movement registration technique (e.g., Jarodzka, Scheiter, Gerjets, \& van Gog, 2010; see also Van Gog \& Scheiter, 2010). On the basis of previous studies on the anticipation processes (e.g., Didierjean \& Marmèche, 2005), it could be predicted, for example, that during the pauses, experts would allocate their visual attention to the probable (future) position of players in the next step. Conversely, novices would allocate their attention to the previous step in order to mentally represent the former position of players and compare it with their present position. Additionally, it would be interesting to investigate the effect of adding a task of recollecting details of the previous step and/or a task of predicting the next step during the pauses on learning outcomes (Paas, Van Gerven, \& Wouters, 2007). Besides, a number of studies have measured the invested mental effort not only after the study phase, but also after the test phase (e.g., Kester, Kirschner, \& Van Merriënboer, 2006; Paas et al., 2007). As mentioned by Van Gog and Paas (2008), the combination of performance and mental effort after the test phase could be considered as an indicator of learners' achieved level of expertise (i.e., the quality and the quantity of the constructed schemas), and hence, this measurement could also be used outside instructional contexts in order to assess levels of expertise in the field (Van Gog, Paas, \& Van Merriënboer, 2005). Thus, this measurement should also be used in future research in this domain. Finally, this study demonstrated that simulated animations of soccer scenes captured efficiently the essence of domain-specific knowledge during task achievement. However, employing such visual representations does not offer a valid ecological context to elucidate how training cognitiveperceptual aspects (i.e., from animations) influence the player's physical behavior-motor action-in real condition. As such, examination of findings of this study in real competitive situations (i.e., under field conditions) is recommended.

The present findings have important implications for educational practice, in the sense that they encourage coaches to use different forms of segmentation to support the tactical learning of learners with different level of expertise. These types of visual representations facilitate the integration of the exact players' positions that learners will have to reproduce and perform later when on the field. In summary, this study underlines the benefit of employing different forms of segmentation in improving learning from an animated soccer scene, as well as the need to consider levels of player expertise when selecting appropriate forms of segmentation. Novice players may benefit more from micro-step segmentation than from macro-step segmentation or no segmentation and more from macro-step segmentation than from no segmentation, while expert players may benefit similarly from both types of segmentation.

\section{References}

Abernethy, B., Neal, R. J., \& Koning, P. (1994). Visual-perceptual and cognitive differences between expert, intermediate and novice snooker players. Applied Cognitive Psychology, 8, 185-211. http://dx.doi.org/10.1002/acp.2350080302.

Ainsworth, S., \& Van Labeke, N. (2004). Multiple forms of dynamic representation. Learning and Instruction, 14, 241-255. http://dx.doi.org/10.1016/ j.learninstruc.2004.06.002.

Araújo, D., Travassos, B., \& Vilar, L. (2010). Tactical skills are not verbal skills: a comment on Kannekens and colleagues. Perceptual and Motor Skills, 110, 1086-1088, Retrieved from. http://www.ncbi.nlm.nih.gov.

Ayres, P., \& Paas, F. (2007). Making instructional animations more effective: a cognitive load approach. Applied Cognitive Psychology, 21, 695-700. http:// dx.doi.org/10.1002/acp.1351.

Baddeley, A. (2003). Working memory: looking back and looking forward. Nature Reviews: Neuroscience, 4, 828-839. http://dx.doi.org/10.1038/nrn1201.

Barak, M., Ashkar, T., \& Dori, Y. (2011). Learning science via animated movies: it's effect on students' thinking and motivation. Computers \& Education, 56, 839846. http://dx.doi.org/10.1016/j.compedu.2010.10.025.

Bétrancourt, M. (2005). The animation and interactivity principles in multimedia learning. In R. E.Mayer (Ed.), The Cambridge handbook of multimedia learning (pp. 287-296). New York: Cambridge University Press.

Boucheix, J.-M., \& Schneider, E. (2009). Static and animated presentations in learning dynamic mechanical systems. Learning and Instruction, 19(2), 112-127. http://dx.doi.org/10.1016/j.learninstruc.2008.03.004.

Carling, C., Reilly, T., \& Williams, A. M. (2008). Assessment of performance in field sports. London: Taylor and Francis.

Chandler, P. (2009). Dynamic visualizations and hypermedia: beyond the 'Wow' factor. Computers in Human Behavior, 25, 389-392. http://dx.doi.org/10.1016/ j.chb.2008.12.018.

Chase, W. G., \& Simon, H. A. (1973). Perception in chess. Cognitive Psychology, 4, 5581. http://dx.doi.org/10.1016/0010-0285(73)90004-2.

De Koning, B. B., Tabbers, H. K., Rikers, R. M. J. P., \& Paas, F. (2007). Attention cueing as a means to enhance learning from an animation. Applied Cognitive Psychology, 21, 731-746. http://dx.doi.org/10.1002/acp.

De Koning, B. B. Tabbers, H. K. Rikers, R. M. J. P. \& Paas, F. (2010). Attention guidance in learning from a complex animation: seeing is understanding? Learning and Instruction, 20, 111-122. http://dx.doi.org/10.1016/ j.learninstruc.2009.02.010.

Didierjean, A., \& Marmèche, E. (2005). Anticipatory representation of visual basketball scenes by novice and expert players. Visual Cognition, 12, 265-283. http://dx.doi.org/10.1080/13506280444000021. 
Hasler, B. S., Kersten, B., \& Sweller, J. (2007). Learner control, cognitive load and instructional animation. Applied Cognitive Psychology, 21, 713-729. http:// dx.doi.org/10.1002/acp.1345.

Hegarty, M. (1992). Mental animation: inferring motion from static displays of mechanical systems. Journal of Experimental Psychology: Learning, Memory, and Cognition, 18, 1084-1102. http://dx.doi.org/10.1037/0278-7393.18.5.1084.

Hegarty, M., Kriz, S., \& Cate, C. (2003). The roles of mental animations and external animations in understanding mechanical systems. Cognition and Instruction, 21, 325-360. http://dx.doi.org/10.1207/s1532690xci2104_1.

Höffler, T. N., \& Leutner, D. (2007). Instructional animation versus static pictures: a meta-analysis. Learning and Instruction, 17, 722-738. http://dx.doi.org/ 10.1016/j.learninstruc.2007.09.013.

Jarodzka, H., Scheiter, K., Gerjets, P., \& van Gog, T. (2010). In the eyes of the beholder: how experts and novices interpret dynamic stimuli. Learning and Instruction, 20 , 146-154. http://dx.doi.org/10.1016/j.learninstruc.2009.02.019.

Johnson, J. G., \& Raab, M. (2003). Take the first: option generation and resulting choices. Organizational Behavior and Human Decision Processes, 91, 215-229. http://dx.doi.org/10.1016/S0749-5978(03)00027-X.

Kalyuga, S. (2007). Expertise reversal effect and its implications for learner-tailored instruction. Educational Psychology Review, 19, 509-539. http://dx.doi.org/ 10.1007/s10648-007-9054-3.

Kalyuga, S. (2008). Relative effectiveness of animated and static diagrams: an effect of learner prior knowledge. Computers in Human Behavior, 24, 852-861. http:// dx.doi.org/10.1016/j.chb.2007.02.018

Kalyuga, S., Ayres, P., Chandler, P., \& Sweller, J. (2003). The expertise reversal effect. Educational Psychologist, 38, 23-31. http://dx.doi.org/10.1207/ S15326985EP3801 4.

Kalyuga, S., Rikers, R., \& Paas, F. (2012). Educational implications of expertise reversal effects in learning and performance of complex cognitive and sensorimotor skills. Educational Psychology Review, 24, 313-337.

Kester, L., Kirschner, P. A., \& Van Merriënboer, J. J. G. (2006). Just-in-time information presentation: improving learning a troubleshooting skill. Contemporary Educational Psychology, 31, 167-185. http://dx.doi.org/10.1016/ j.cedpsych.2005.04.002.

Kriz, S., \& Hegarty, M. (2007). Top-down and bottom-up influences on learning from animations. International Journal of Human Computer Studies, 65, 911-930. http://dx.doi.org/10.1016/j.ijhcs.2007.06.005.

Lowe, R. K. (1999). Extracting information from an animation during complex visual learning. European Journal of Psychology of Education, 14, 225-244. http:// dx.doi.org/10.1007/BF03172967.

Lowe, R. K. (2003). Animation and learning selective processing of information in dynamic graphics. Learning and Instruction, 13, 157-176. http://dx.doi.org/ 10.1016/S0959-4752(02)00018-X.

Lowe, R. K. (2004). Interrogation of a dynamic visualization during learning Learning and Instruction, 14, 257-274. http://dx.doi.org/10.1016/ j.learninstruc.2004.06.003.

Mayer, R. E., \& Chandler, P. (2001). When learning is just a click away: does simple user interaction foster deeper understanding of multimedia messages? Journal of Educational Psychology, 93, 390-397. http://dx.doi.org/10.1037/00220663.93.2.390.

Mayer, R. E., DeLeeuw, K. E., \& Ayres, P. (2007). Creating retroactive and proactive Interference in Multimedia Learning. Applied Cognitive Psychology, 21, 795-809. http://dx.doi.org/10.1002/acp.1350.

Mayer, R. E., Hegarty, M., Mayer, S., \& Campbell, J. (2005). When static media promotes active learning: annotated illustrations versus narrated animations in multimedia instruction. Journal of Experimental Psychology: Applied, 11, 256265. http://dx.doi.org/10.1037/1076-898X.11.4.256.

Mayer, R. E., \& Moreno, R. (2003). Nine ways to reduce cognitive load in multimedia learning. Educational Psychologist, 38, 43-52. http://dx.doi.org/10.1207/ S15326985EP3801_6.

Meyer, K., Rasch, T., \& Schnotz, W. (2010). Effects of animation's speed of presentation on perceptual processing and learning. Learning and Instruction, 20, 136145. http://dx.doi.org/10.1016/j.learninstruc.2009.02.016.

Mohamad Ali, A. Z. (2010). Effects of teacher controlled segmented-animation presentation in facilitating learning. Journal of Educational Multimedia and Hypermedia, 19, 367-378, Retrieved from. http://www.aace.org/pubs/jemh/.

Moreno, R. (2007). Optimising learning from animations by minimising cognitive load: cognitive and affective consequences of signalling and segmentation methods. Applied Cognitive Psychology, 21, 765-781. http:// dx.doi.org/10.1002/acp

Moreno, R., \& Mayer, R. (2007). Interactive multimodal learning environments. Educational Psychology Review, 19, 309-326. http://dx.doi.org/10.1007/s10648 007-9047-2.
Paas, F. (1992). Training strategies for attaining transfer of problem-solving skill in statistics: a cognitive-load approach. Journal of Educational Psychology, 84, 429434. http://dx.doi.org/10.1037/0022-0663.84.4.429.

Paas, F., Tuovinen, J., Tabbers, H., \& Van Gerven, P. W. M. (2003). Cognitive load measurement as a means to advance cognitive load theory. Educational Psychologist, 38, 63-71. http://dx.doi.org/10.1207/S15326985EP3801_8.

Paas, F., Van Gerven, P. W. M., \& Wouters, P. (2007). Instructional efficiency of animation: effects of interactivity through mental reconstruction of static key frames. Applied Cognitive Psychology, 21, 783-793. http://dx.doi.org/10.1002/ acp.1349.

Paas, F. G. W. C., \& van Merrienboer, J. J. G. (1993). The efficiency of instructiona conditions: an approach to combine mental-effort and performance measures. Human Factors, 35, 737-743, Retrieved from. http://hfs.sagepub.com/.

Pinder, R. A., Davids, K. W., Renshaw, I., \& Araújo, D. (2011). Representative learning design and functionality of research and practice in sport. Journal of Sport and Exercise Psychology, 33, 146-155, Retrieved from. www.ncbi.nlm.nih.gov.

Poplu, G., Baratgin, J., Mavromatis, S., \& Ripoll, H. (2003). What kind of processes underlie decision-making in soccer simulation? An implicit-memory investigation. International Journal of Sport and Exercise Psychology, 1, 390-405. http:// dx.doi.org/10.1080/1612197X.2003.9671727.

Schnotz, W. (2002). Enabling, facilitating and inhibiting effects in learning from animated pictures. Paper presented at the International Workshop on Dynamic Visualizations and Learning, Tübingen, Germany.

Schnotz, W., \& Lowe, R. (2008). A unified view of learning from animated and static graphics. In R. Lowe, \& W. Schnotz (Eds.), Learning with animations: Research implications for design (pp. 304-356). New York: Cambridge University Press.

Spanjers, I. A. E., Van Gog, T., \& Van Merriënboer, J. J. G. (2010). A theoretical analysis of how segmentation of dynamic visualizations enhances students' learning. Educational Psychology Review, 22, 411-423. http://dx.doi.org/10.1007/s10648010-9135-6.

Spanjers, I. A. E., Van Gog, T., Wouters, P., \& Van Merriënboer, J. J. G. (2012) Explaining the segmentation effect in learning from animations: the role of pausing and temporal cueing. Computers \& Education, 59, 274-280. http:// dx.doi.org/10.1016/j.compedu.2011.12.024.

Spanjers, I. A. E., Wouters, P., Van Gog, T., \& Van Merriënboer, J. J. G. (2011). An expertise reversal effect of segmentation in learning from animations. Computers in Human Behavior, 27, 46-52. http://dx.doi.org/10.1016/ j.chb.2010.05.011.

Stratton, G., Reilly, T., Williams, A. M., \& Richardson, D. R. (2005). Science of youth soccer. London: Taylor and Francis.

Sweller, J. (2005). Implication of cognitive load theory for multimedia learning. In R. Mayer (Ed.), The Cambridge handbook of multimedia learning (pp. 19-30). Cambridge: Cambridge University Press.

Sweller, J., Ayres, P., \& Kalyuga, S. (2011). Cognitive load theory. New York: Springer.

Sweller, J., van Merriënboer, J. J. G., \& Paas, F. (1998). Cognitive architecture and instructional design. Educational Psychology Review, 10, 251-296. http:// dx.doi.org/10.1023/A:1022193728205

Tversky, B., Morrison, J. B., \& Betrancourt, M. (2002). Animation: can it facilitate? International Journal of Human-Computer Studies, 57, 247-262. http://dx.doi.org/ 10.1006/ijhc.2002.1017.

Van Gog T \& Paas, F. (2008). Instructional efficiency: revisiting the original construct in educational research. Educational Psychologist, 43, 16-26. http:// dx.doi.org/10.1080/00461520701756248.

Van Gog, T., Paas, F., Marcus, N., Ayres, P., \& Sweller, J. (2009). The mirror-neuron system and observational learning: implications for the effectiveness of dynamic visualisations. Educational Psychology Review, 21, 21-30. http:// dx.doi.org/10.1007/s10648-008-9094-3.

Van Gog, T., Paas, F., \& Van Merriënboer, J. J. G. (2005). Uncovering expertise-related differences in troubleshooting performance: combining eye movement and concurrent verbal protocol data. Applied Cognitive Psychology, 19, 205-221. http://dx.doi.org/10.1002/acp.1112.

Van Gog, T. \& Scheiter, K. (2010). Eye tracking as a tool to study and enhance multimedia learning. Learning and Instruction, 20, 95-99. http://dx.doi.org/ 10.1016/j.learninstruc.2009.02.009.

Van Merriënboer, J. J. G., \& Sweller, J. (2005). Cognitive load theory and complex learning: recent developments and future directions. Educational Psychology Review, 17, 147-177. http://dx.doi.org/10.1007/s10648-005-3951-0.

Wouters, P., Paas, F., \& Van Merriënboer, J. J. G. (2008). How to optimize learning from animated models: a review of guidelines based on cognitive load. Revie$w$ of Educational Research, 78, 645-675. http://dx.doi.org/10.3102/ 0034654308320320.

Zacks, J. M., \& Tversky, B. (2001). Event structure in perception and conception. Psychological Bulletin, 127, 3-21. http://dx.doi.org/10.1037/0033-2909.127.1.3. 